\title{
Near-IR-Triggered, Remote-Controlled Release of Metal Ions: A Novel Strategy for Caged Ions**
}

\author{
Ahmet Atilgan, Esra Tanriverdi Eçik, Ruslan Guliyev, T. Bilal Uyar, Sundus Erbas-Cakmak, and \\ Engin U. Akkaya*
}

\begin{abstract}
A ligand incorporating a dithioethenyl moiety is cleaved into fragments which have a lower metal-ion affinity upon irradiation with low-energy red/near-IR light. The cleavage is a result of singlet oxygen generation which occurs on excitation of the photosensitizer modules. The method has many tunable factors that could make it a satisfactory caging strategy for metal ions.
\end{abstract}

$T_{\text {he remote manipulation of molecular or ionic concentra- }}$ tions at will, especially in well-defined compartments, such as cells, organelles, or in vivo in tissues, is very important, as it provides an unparalleled capability to control biochemical processes. ${ }^{[1]}$ Caged compounds, in principle, have such a potential. ${ }^{[2]}$ However, as most uncaging processes involve breaking a covalent bond, there is a strict lower limit for the photonic energy of the light suitable for photochemical uncaging. ${ }^{[3]}$ For nitrobenzyl derivatives and related moieties the lowest-energy limit is approximately $\lambda=360 \mathrm{~nm}$. Although for some other molecules the lowest-energy limit can be pushed back to $\lambda=400-450 \mathrm{~nm}$, there is a penalty in the form of significantly decreased reaction quantum yields and diminished conversion efficiencies. ${ }^{[4]}$ Unfortunately, this requirement for UV or blue-light excitation limits the applicability severely as a result of potential photodamage to cells, high scatter, and light absorption in biological media resulting in very poor tissue penetration. ${ }^{[5]}$ The problem can be circumvented by a few techniques, such as two-photon excitation, X-ray photolysis, or by incorporating upconverting nanoparticles (UCNP). ${ }^{[6]}$ Each of the three techniques have advantages and disadvantages, and although they offer palliative solutions, they may also introduce limitations/ problems of their own, such as the toxicity of UCNPs,

[*] A. Atilgan, Dr. E. Tanriverdi Eçik, T. B. Uyar, Dr. S. Erbas-Cakmak, Prof. Dr. E. U. Akkaya

UNAM- National Nanotechnology Research Center

Bilkent University

06800 Ankara (Turkey)

E-mail: eua@fen.bilkent.edu.tr

Dr. E. Tanriverdi Eçik

Department of Chemistry, Gebze Institute of Technology

41400 Kocaeli (Turkey)

Dr. R. Guliyev, Prof. Dr. E. U. Akkaya

Department of Chemistry, Bilkent University

06800 Ankara (Turkey)

[***] Funding from TUBITAK (113T043) is gratefully acknowledged. R.G. and T.B.U. acknowledge support from TUBITAK in the form of postdoctoral and doctoral scholarships.

D. Sur Supporting information for this article is available on the WWW under http://dx.doi.org/10.1002/anie.201405462. a limited focal region for the two-photon techniques, and possible requirements for redesign of the cages.

In recent years, a cleavage reaction has been investigated which is dependent on the generation of singlet oxygen through photosensitization of dissolved molecular oxygen. ${ }^{[7]}$ The process has some similarities to photodynamic action but with one key difference: generated singlet oxygen reacts with an electron-rich alkene (dialkylthio- or dialkoxy-substituted) in the designed microenvironment, resulting in the cleavage of the molecule into two fragments at the site of the electronrich alkene. ${ }^{[8]}$ The reaction is efficient and can be driven by very low-energy light $(\lambda=650-900 \mathrm{~nm}) .{ }^{[9]}$ This use of lowenergy light could be a major advantage if the fragmentation event is linked to a biological process.

In our design, we wanted to use low-energy radiation to remotely release biologically relevant metal ions on demand. $\mathrm{Zn}^{2+}$ is an important target for caging, as changing concentrations of labile zinc ions are involved in a number of pathological conditions, including the development of prostate cancer and Alzheimer's disease. ${ }^{[1 \mathrm{c}, 10]}$ In addition, a modular design was employed so that with minimal synthetic changes to the modules the type of the metal ion to be caged/ released and the excitation wavelength could be changed.

Our proof of principle design (Figure 1) incorporates symmetric structures to simplify the synthetic procedure. With this in mind, brominated di-styryl bodipy units (bodipy $=$ boron dipyrromethene), with absorption maxima in the red region of the electromagnetic spectrum and mesoazido substituents, were prepared (Supporting Information). Through the azido moieties, these units can undergo "click" reactions with the specially crafted alkynyl-substituted dithioethenyl unit (Figure 2). $\mathrm{Zn}^{2+}$ ions should preferentially coordinate to the nitrogen donor atoms rather than the sulfur donors of the "labile" linker, and the click reaction itself potentially contributes two new $\mathrm{N}$-donor atoms on both sides of the linker (Figure 1). In this case, the copper(I) catalyst is strongly deactivated by the ligand and standard click reaction conditions were ineffective. An alternative copper(I) complex, developed by Özçubukçu et al. ${ }^{[11]}$ for difficult reactions of this type, was used with satisfactory results.

In our design, the photosensitizer is an integral part of the cage molecule and is not added externally. The advantage of this strategy is obvious in terms of reaction efficiency. Additionally, the modular design of the system allows us to choose a sensitizer that could absorb in any region of the spectrum, especially in the near-IR region, and is independent of the ligand design (Figure 2).

The ligand design, in principle, can be modified by placing alternative donor groups, chelating groups, or even carbox- 

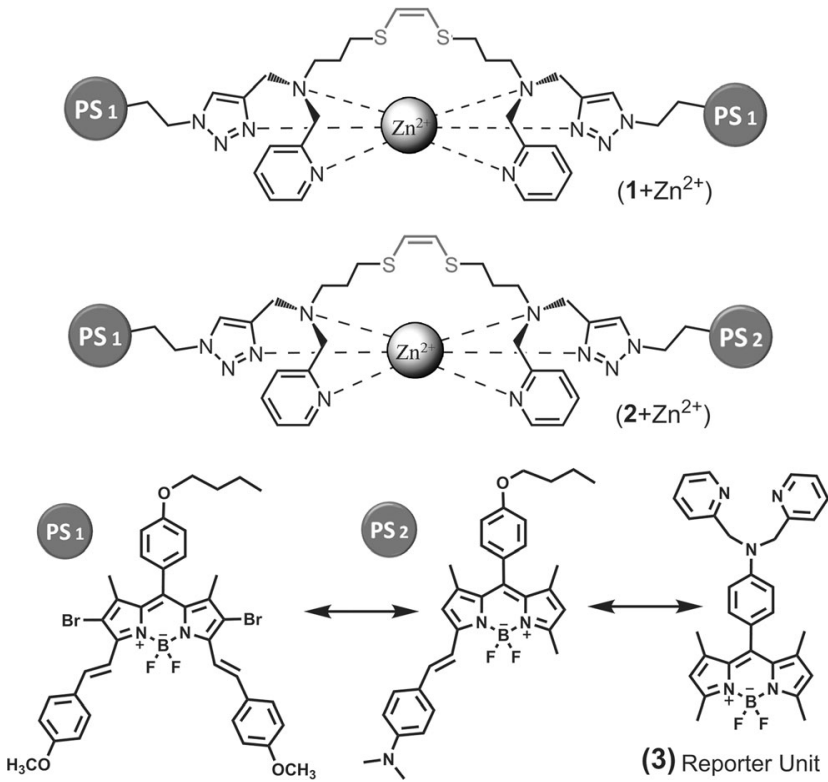

Figure 1. Structural formula of cage ligands (1 and 2 ), the corresponding caged $\mathrm{Zn}^{2+}$ compounds $\left(\mathbf{1}+\mathrm{Zn}^{2+}\right.$ and $\left.\mathbf{2}+\mathrm{Zn}^{2+}\right)$, and the reporter molecule 3. PS = photosensitizer unit.

ylate moieties (for alkaline and alkaline-earth cations), on the thiol substituents. The current design $\left(\mathrm{PS}_{1}\right)$ is anticipated to work optimally at an excitation wavelength of $\lambda=660 \mathrm{~nm}$. To follow the progress of the uncaging reaction, that is, the release of $\mathrm{Zn}^{2+}$ ions, we chose to employ a bodipy-based (BOD) fluorescent reporter of zinc(II), with a dipicolylamine (DPA) ligand (3; DPA-BOD). This reporter molecule has a rapid and strong response to increasing zinc concentrations with an increasing emission intensity. ${ }^{[12]}$ The binding strength and stoichiometry of compounds $\mathbf{1}$ and $\mathbf{2}$ to $\mathrm{Zn}^{2+}$ ions was studied with isothermal titration calorimetry (ITC) by using a model compound (page S17, Figure S47, Supporting Information). The model compound clearly shows a 1:1 binding stoichiometry, and a binding constant of $2.6 \times 10^{5} \mathrm{M}^{-1}$ was calculated. Additionally, a +2 charged species with the correct $\mathrm{m} / \mathrm{z}$ ratio was identified for the $1: 1 \mathrm{zinc}(\mathrm{II})$ complex (page S17, Figures S44, S45, Supporting Information).

The zinc(II) release process (Figure 3 ) is initiated by absorption of a photon of light, in this case, it is a photon of red light $(\lambda=660 \mathrm{~nm})$. The photosensitizer undergoes rapid excitation to access the triplet excited state as a result of the heavy atoms in the system (in this case two bromine atoms) which facilitate intersystem crossing. Energy transfer to

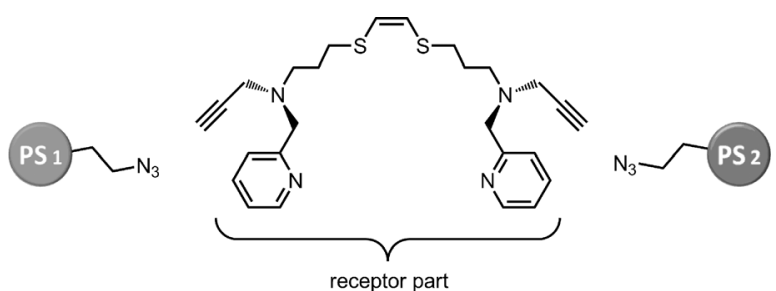

Figure 2. Modular design and synthetic route to prepare the proposed cage ligands (1 and 2 ).
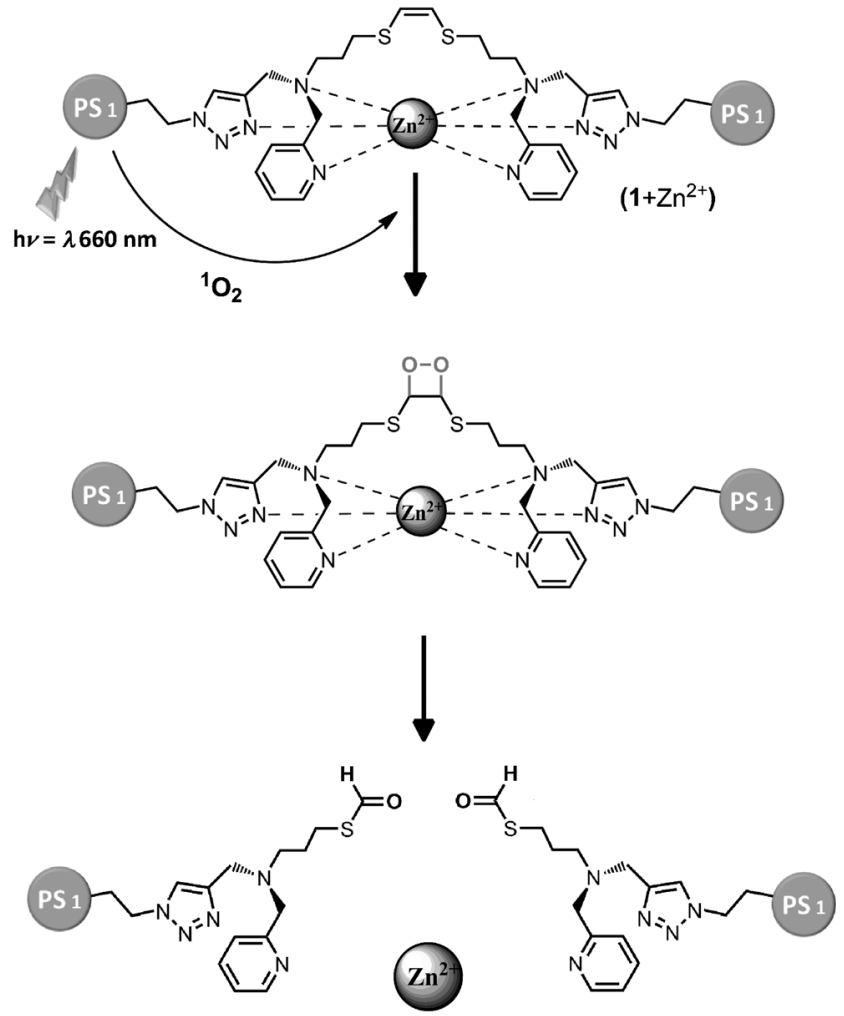

Figure 3. Working principle to activate the caged $\mathrm{Zn}^{2+}$ compound $\left(1+\mathrm{Zn}^{2+}\right)$ by light of any required energy. $h v=$ incident light absorbed by the PS

dissolved molecular oxygen follows to generate singlet oxygen, which undergoes addition to the double bond to form a reactive dioxetane ring. Thermal ring opening at room temperature results in the cleavage products. The ligand itself is cleaved into two pieces which will have significantly lower affinity for $\mathrm{Zn}^{2+}$ ions. The net result is a release of metal ions.

Based on the above strategy, the uncaging experiment was then carried out by the irradiation of the caged $\mathrm{Zn}^{2+}$ complex, which was prepared by the addition of one equivalent of $\mathrm{Zn}^{2+}$ ions to a solution of ligand $\mathbf{1}$ in the presence of the reporter molecule 3. The solution was irradiated with filtered broadband white light where wavelengths shorter than $\lambda=400 \mathrm{~nm}$ had been removed. Aliquots of the irradiated solution were taken at four-minute intervals and the fluorescence of the $\mathrm{Zn}^{2+}$ reporter molecule was determined (Figure 4).

With increasing irradiation time, the emission intensity of the probe $\mathbf{3}$ increased steadily, demonstrating the release of $\mathrm{Zn}^{2+}$ from the molecular cage. Alternative possibilities that might lead to an emission increase at $\lambda=510 \mathrm{~nm}$ were experimentally tested and eventually eliminated. For example, in the absence of irradiation, no change in the emission intensity of the probe is detected when mixed with the caged $\mathrm{Zn}^{2+}$ species, attesting to the higher affinity of the cage for $\mathrm{Zn}^{2+}$ ions compared to the probe 3 . In the absence of the probe itself, no change in the emission is detected in the $\lambda=$ $510 \mathrm{~nm}$ region of the spectrum upon irradiation of the cage compound at $\lambda=660 \mathrm{~nm}$. Additional control experiments also demonstrated that the singlet oxygen produced on excitation does not interfere with the photoluminescence 


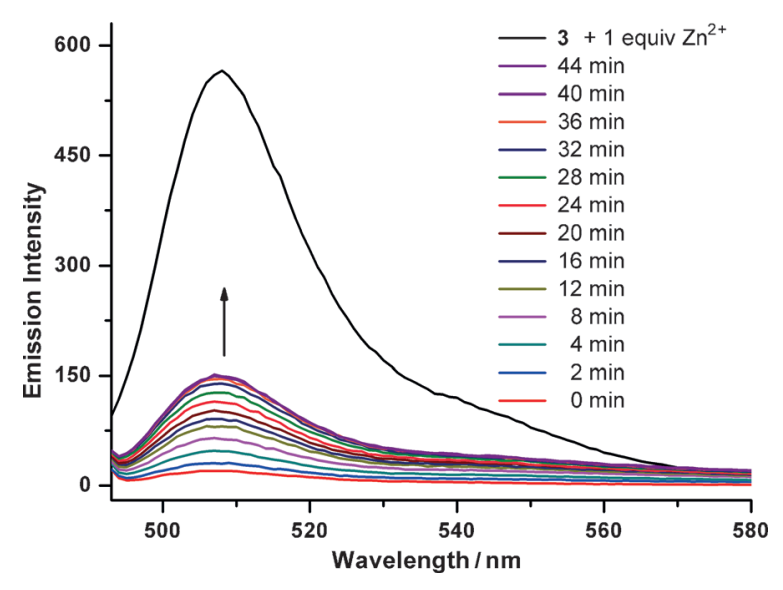

Figure 4. Emission spectra showing the fluorescence response of compound 3 (DPA-BOD) after uncaging of $1+\mathrm{Zn}^{2+}(5.0 \mu \mathrm{M}$ each) by light irradiation (recorded in $\mathrm{CH}_{3} \mathrm{CN}$ ). Time values indicate the duration of irradiation with the Xe lamp (wavelengths of higher energy than $\lambda=400 \mathrm{~nm}$ filtered out). Irradiation results in the photolysis of the $\mathrm{Zn}^{2+}$ complex $\mathbf{1}+\mathrm{Zn}^{2+}$ and is followed by an increase in emission intensity due to the formation of the $3+Z^{2+}$ complex $\left(\lambda_{\text {ex }}=490 \mathrm{~nm}\right)$ Highest intensity emission trace represents the maximum emission intensity of $\mathbf{3}$ (DPA-BOD) obtained by the addition of 1.0 equivalents of zinc(II) ions in the form of the triflate salt.

signal detected upon $\mathrm{Zn}^{2+}$ binding to the reporter compound 3 (Figure S8).

The singlet oxygen quantum yield of the current system using $\mathrm{PS}_{1}$ as the photosensitizer dyes was determined to be 0.14 (Supporting Information). Despite the modest efficiency, application of this photosensitizer resulted in impressive uncaging of zinc(II) ions. Replacement of the chromophore with a more efficient photosensitizer is anticipated to generate more effective uncaging by molecular cleavage.

We next sought to demonstrate the ability of an energytransfer cassette to affect the uncaging process. To that end, asymmetric compound $\mathbf{2}$ was synthesized (Figure 1). In this molecule, the dye $\mathrm{PS}_{2}$, with a shorter wavelength absorption maxima $(\lambda=600 \mathrm{~nm})$ and a larger extinction coefficient, is employed. In molecule $\mathbf{2}, \mathrm{PS}_{2}$ is the primary excitation target, and as it does not contain heavy atoms, it is not expected to undergo efficient intersystem crossing. However, from the $\mathrm{PS}_{2}$ moiety, excited-state energy transfer (EET) is possible. ${ }^{[13]}$ When EET takes place to the other chromophore module $\left(\mathrm{PS}_{1}\right)$, singlet oxygen is generated as a result of the heavy atom effect of the bromine atoms on that bodipy core. This again leads to the cleavage of the alkene, releasing fragments of the original ligand which have a lower binding affinity for $\mathrm{Zn}^{2+}$ ions, and uncaging $\mathrm{Zn}^{2+}$ ions which are then reported by the reporter compound 3 (Figure 5). Using a broadband excitation source, we were able to excite the photosensitizer both directly and by energy transfer, which is expected to yield a higher efficiency in the uncaging process. The proportional increase in emission intensity is higher under these conditions, demonstrating that $\mathrm{Zn}^{2+}$ release can be coupled to intramolecular energy transfer. This experiment shows that the antenna effect can be utilized for more effective uncaging and metal-ion release.

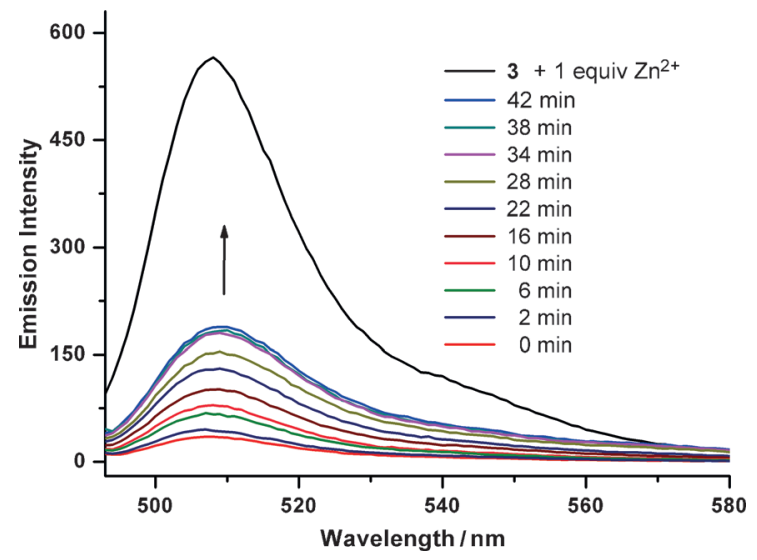

Figure 5. Emission spectra showing the fluorescence response of compound 3 (DPA-BOD) after uncaging of $\mathbf{2}+\mathrm{Zn}^{2+}(5.0 \mu \mathrm{M}$ each) by light irradiation (recorded in $\mathrm{CH}_{3} \mathrm{CN}$ ). Time values indicate the duration of irradiation with the Xe lamp (wavelengths of higher energy than $\lambda=400 \mathrm{~nm}$ filtered out). Compound 3 initially exhibits low fluorescence (quenched due to the active PET process). Irradiation results in the photolysis of the $\mathbf{2}+\mathrm{Zn}^{2+}$ complex and is followed by the enhanced emission intensity of $3\left(\lambda_{\mathrm{ex}}=490 \mathrm{~nm}\right)$. Highest intensity emission intensity represents the maximum emission intensity of 3 (DPA-BOD) obtained by the addition of 1.0 equivalents of zinc(II) ions in the form of the triflate salt.

The efficiency of the uncaging process was then compared with an established $o$-nitrobenzyl-containing caged $\mathrm{Zn}^{2+}$ compound $^{[14]}$ (which is structurally similar to a well-studied cage ligand $\left.{ }^{[4 a]}\right)$ under the same conditions. Excitation at $\lambda=$ $360 \mathrm{~nm}$ of the $o$-nitrobenzyl caged compounds results in a similar photoluminescence signal enhancement in the reporter molecule (Figure 6) as detected for the symmetric cage system $\left(\mathbf{1}+\mathrm{Zn}^{2+}\right)$, but less than the asymmetric system $\left(2+\mathrm{Zn}^{2+}\right)$. In other words, better results were obtained in terms of percent $\mathrm{Zn}^{2+}$ release under lower energy irradiation $(\lambda=660 \mathrm{~nm})$, when compared to that of $o$-nitrobenzyl cages

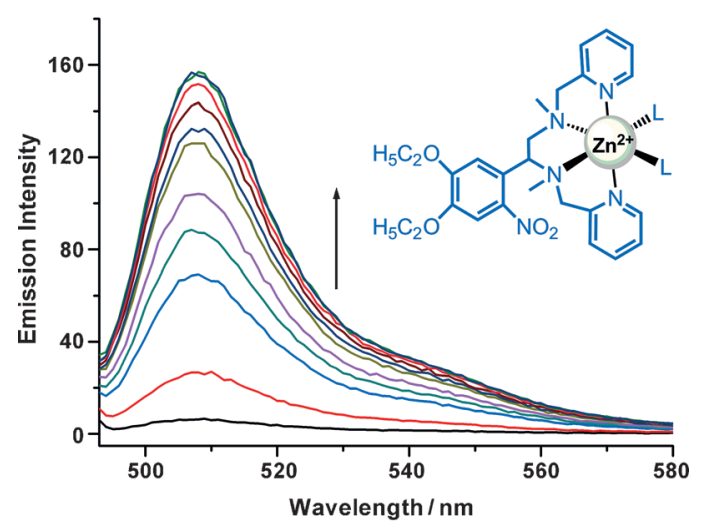

Figure 6. Emission spectra showing the fluorescence response of compound $\mathbf{3}$ after uncaging of one equivalent of o-nitrobenzyl $\mathrm{Zn}^{2+}$ cage complex (5.0 $\mu \mathrm{M}$ each) by light irradiation (recorded in $\mathrm{CH}_{3} \mathrm{CN}$ ). Compound 3 (DPA-BOD) initially exhibits no fluorescence (quenched due to the active PET process). As the solution was irradiated at $\lambda=360 \mathrm{~nm}$ (for $10 \mathrm{~min}$ ) the increase in the emission intensity levels off, which can be interpreted as the completion of photolysis of the $\mathrm{Zn}^{2+}$ cage compound. 
under UV irradiation. The percentage of zinc(II) released following irradiation can be quantified. The area underneath the emission band for one equivalent of $\mathrm{Zn}^{2+}$ ions in the presence of the reporter unit $\mathbf{3}$ can be set to correspond to $100 \%$ free $\mathrm{Zn}^{2+}$ ions. By comparison, the ratios of the emission band areas will yield the relative amounts of $\mathrm{Zn}^{2+}$ ions released. By this method, $31 \% \mathrm{Zn}^{2+}$ ion release is calculated for compound $\mathbf{1}+\mathrm{Zn}^{2+}$, whereas asymmetric compound $\mathbf{2}+\mathrm{Zn}^{2+}$ leads to $40 \%$ free $\mathrm{Zn}^{2+}$. Under comparable conditions, that is, when the emission intensity increase has leveled off in acetonitrile, $29 \%$ of the $o$-nitrobenzyl caged zinc compound (Figure 6) releases its bound $\mathrm{Zn}^{2+}$ ions which are reported by the fluorescent $\mathrm{Zn}^{2+}$ probe. These values do not imply incomplete reactions as some fraction of the $\mathrm{Zn}^{2+}$ may not be available to the reporter compound as a result of residual affinity of the cleaved fragments for $\mathrm{Zn}^{2+}$ ions.

In conclusion, we report a novel modular design for caging ligands and red to near-IR light-triggered uncaging of $\mathrm{Zn}^{2+}$ ions from that cage. This is the first example of metalion uncaging using more penetrating lower-energy red to near-IR light without using upconversion, X-rays, or twophoton techniques. There is substantial potential for the application of systems of this type in biological systems including model organisms (in vivo), and further work may be also expected to yield designer cages for therapeutic applications.

Received: May 20, 2014

Revised: June 30, 2014

Published online: August 11, 2014

Keywords: caged compounds · photochemistry .

photosensitizers $\cdot$ singlet oxygen $\cdot$ zinc

[1] a) S. Yamasaki, K. Sakata-Sogawa, A. Hasegawa, T. Suzuki, K. Kabu, E. Sato, T. Kurosaki, S. Yamashita, M. Tokunaga, K Nishida, T. Hirano, J. Cell Biol. 2007, 177, 637-645; b) M. J. Berridge, M. D. Bootman, P. Lipp, Nature 1998, 395, 645-648; c) C. J. Frederickson, J. Y. Koh, A. I. Bush, Nat. Rev. Neurosci. 2005, 6, 449-462; d) C. F. Walker, R. E. Black, Annu. Rev. Nutr. 2004, 24, 255-275; e) P. J. Fraker, L. E. King, Annu. Rev. Nutr. 2004, 24, 277-298.

[2] a) G. C. R. Ellis-Davies, Chem. Rev. 2008, 108, 1603-1613; b) G. C. R. Ellis-Davies, Nat. Methods 2007, 4, 619-628; c) S. R. Adams, J. P. Y. Kao, G. Grynkiewicz, R. Y. Tsien, J. Am. Chem. Soc. 1988, 110, 3212-3220; d) S. Adams, R. Tsien, Annu. Rev. Physiol. 1993, 55, 755-784; e) H. Yu, J. Li, D. Wu, Z. Qiu, Y. Zhang, Chem. Soc. Rev. 2010, 39, 464-473.

[3] a) P. Klán, T. Solomek, C. G. Bochet, A. Blanc, R. Givens, M. Rubina, V. Popik, A. Kostikov, J. Wirz, Chem. Rev. 2013, 113, 119-191; b) A. P. Pelliccioli, J. Wirz, Photochem. Photobiol. Sci. 2002, $1,441-458$.

[4] a) H. M. D. Bandara, D. P. Kennedy, E. Akin, C. D. Incarvito, S. C. Burdette, Inorg. Chem. 2009, 48, 8445-8455; b) H. M. D.
Bandara, T. P. Walsh, S. C. Burdette, Chem. Eur. J. 2011, 17, 3932 -3941; c) H. N. Mbatia, H. M. D. Bandara, S. C. Burdette, Chem. Commun. 2012, 48, 5331-5333; d) "Coumarin-4ylmethyl phototriggers": T. Furuta in Dynamic Studies in Biology (Eds.: M. Goeldner, R. S. Givens), Wiley-VCH, Weinheim, 2006, p. 29.

[5] R. Weissleder, Nat. Biotechnol. 2001, 19, 316-317.

[6] a) Y. H. Chien, Y. L. Chou, S. W. Wang, S. T. Hung, M. C. Liau, Y. J. Chao, C. H. Su, C. S. Yeh, ACS Nano 2013, 7, 8516-8528; b) C.-J. Carling, F. Nourmohammadian, J.-C. Boyer, N. R. Branda, Angew. Chem. 2010, 122, 3870-3873; Angew. Chem. Int. Ed. 2010, 49, 3782-3785; c) M. K. G. Jayakumar, M. Idris, Y. Zhang, Proc. Natl. Acad. Sci. USA 2012, 109, 8483-8488; d) C. Wang, L. Cheng, Z. Liu, Theranostics 2013, 3, 317-330; e) G. Bort, T. Gallavardin, D. Ogden, P. I. Dalko, Angew. Chem. 2013, 125, 4622-4634; Angew. Chem. Int. Ed. 2013, 52, 4526-4537; f) E. B. Brown, J. B. Shear, S. R. Adams, R. Y. Tsien, W. W. Webb, Biophys. J. 1999, 76, 489-499; g) M. Petit, G. Bort, B.-T. Doan, C. Sicard, D. Ogden, D. Scherman, C. Ferroud, P. I. Dalko, Angew. Chem. 2011, 123, 9882-9885; Angew. Chem. Int. Ed. 2011, 50, 9708-9711; h) K. L. Ciesienski, K. L. Haas, M. G. Dickens, Y. T. Tesema, K. J. Franz, J. Am. Chem. Soc. 2008, 130, 12246-12247; i) "Multiphoton Phototriggers for exploring cell physiology": T. M. Dore in Dynamic Studies in Biology (Eds.: M. Goeldner, R. S. Givens), Wiley-VCH, Weinheim, 2006, p. 435.

[7] a) B. Moses, Y. You, Med. Chem. 2013, 3, 192-198; b) R. S. Murthy, M. Bio, Y. You, Tetrahedron Lett. 2009, 50, 1041-1044.

[8] a) A. Rotaru, A. Mokhir, Angew. Chem. 2007, 119, 6293-6296; Angew. Chem. Int. Ed. 2007, 46, 6180-6183; b) S. D. P. Baugh, Z. Yang, D. Leung, D. M. Wilson, R. Breslow, J. Am. Chem. Soc. 2001, 123, 12488-12494; c) D. Arian, L. Kovbasyuk, A. Mokhir, J. Am. Chem. Soc. 2011, 133, 3972-3980; d) A. Ruebner, Z. Yang, D. Leung, R. Breslow, Proc. Natl. Acad. Sci. USA 1999, 96, $14692-14693$.

[9] a) S. Erbas-Cakmak, E. U. Akkaya, Angew. Chem. 2013, 125, 11574-11578; Angew. Chem. Int. Ed. 2013, 52, 11364-11368; b) S. Erbas-Cakmak, E. U. Akkaya, Org. Lett. 2014, 16, $2946-$ 2949.

[10] a) A. I. Bush, W. H. Pettingell, G. Multhaup, M. D. Paradis, J.-P. Vonsattel, J. F. Gusella, K. Beyreuther, C. L. Masters, R. E. Tanzi, Science 1994, 265, $1464-1467$; b) J. H. Weiss, S. L. Sensi, J. Y. Koh, Trends Pharmacol. Sci. 2000, 21, 395-401; c) L. C. Costello, R. B. Franklin, Mol. Cancer 2006, 5, 17.

[11] S. Özçubukçu, E. Ozkal, C. Jimeno, M. A. Pericàs, Org. Lett. 2009, 11, 4680-4683.

[12] R. Guliyev, S. Ozturk, Z. Kostereli, E. U. Akkaya, Angew. Chem. 2011, 123, 10000-10005; Angew. Chem. Int. Ed. 2011, 50, $9826-$ 9831.

[13] a) A. Harriman, M. A. H. Alamiry, J. P. Hagon, D. Hablot, R. Ziessel, Angew. Chem. 2013, 125, 6743-6747; Angew. Chem. Int. Ed. 2013, 52, 6611-6615; b) D. Hablot, A. Harriman, R. Ziessel, Angew. Chem. 2011, 123, 7979-7982; Angew. Chem. Int. Ed. 2011, 50, 7833-7836; c) T. Bura, P. Retailleau, R. Ziessel, Angew. Chem. 2010, 122, 6809-6813; Angew. Chem. Int. Ed. 2010, 49, 6659-6663; d) R. Ziessel, M. A. H. Alamiry, K. J. Elliott, A. Harriman, Angew. Chem. 2009, 121, 2810-2814; Angew. Chem. Int. Ed. 2009, 58, 2772-2776.

[14] E. Tanrıverdi Ecik, A. Atilgan, R. Guliyev, T. B. Uyar, A. Gumus, E. U. Akkaya, Dalton Trans. 2014, 43, 67-70. 